\title{
A Comparative Study of Ultrasound Biodiesel Production Using Different Homogeneous Catalysts
}

\author{
Kiran Shinde and Serge Kaliaguine * \\ Department of Chemical Engineering, Laval University, Quebec, QC G1 V 0 A6, Canada; \\ kiran.shinde.1@ulaval.ca \\ * Correspondence: serge.kaliaguine@gch.ulaval.ca
}

Received: 30 December 2018; Accepted: 1 February 2019; Published: 11 February 2019

check for updates

\begin{abstract}
Biodiesel (BD) is a liquid fuel that consists of mono alkyl esters of long chain fatty acids derived from vegetable oil or fat. Recently, biodiesel has received additional attention and intense research has been performed in this field due to its favorable atmospheric $\mathrm{CO}_{2}$ balance compared with conventional fossil fuels (net energy balance of 3.0-4.0 MJ/MJ). In this work, a comparison of transesterification of Canola oil with methanol under ultrasound and under mechanical stirring is reported. The general aspects of the ultrasound transesterification process and a comparative study of different types of homogeneous catalysts $\left(\mathrm{NaOH}, \mathrm{KOH}, \mathrm{CH}_{3} \mathrm{ONa}\right.$, tetramethyl ammonium hydroxide and four guanidines) are described. Special attention is given to ultrasound transesterification reaction using guanidines as catalysts.
\end{abstract}

Keywords: ultrasound; transesterification; canola oil; FAME; guanidine

\section{Introduction}

Fossil fuels are the world's primary source of energy. The demand for fossil fuels is increasing day by day. A projected demand for 2030 is 116 million barrels per day [1]. Therefore, searching for alternative green sources has become of primary importance in the field of energy production. Vegetable oil based energy sources, such as biodiesel and other biofuels, can be reliable sources. Biodiesel (BD) is a liquid fuel that consists of mono alkyl esters of long chain fatty acids derived from vegetable oil or fat. Most importantly, $\mathrm{BD}$ is free from sulfur and aromatic components, which makes it environmentally benign. The production of $\mathrm{BD}$ is widely conducted through transesterification using homogeneous or heterogeneous catalysts [2,3]. These catalysts are either acidic [4], basic [5,6] or enzymatic [7] in nature and each kind has its own pros and cons. The most usual ones in the production of $\mathrm{BD}$ are homogeneous basic catalysts that include $\mathrm{KOH}, \mathrm{NaOH}, \mathrm{CH} 3 \mathrm{OK}$ and $\mathrm{CH} 3 \mathrm{ONa}$. Ionic liquids might also be good potential catalysts. Muhammad et al. [8] provide an overview of the possible application of ionic liquids in biodiesel production.

Homogeneous catalysts can be split into two categories: Acid or base catalysts. The process of using homogeneous catalysts involves difficulties in their separation and purification from products. In BD production, methyl esters and glycerol are recovered in two separate phases. The catalyst must be removed in the polar phase, a process that is time-consuming and requires expensive separation steps [9]. Another main disadvantage of base catalysts is the presence of side reactions that form soaps, thus decreasing the BD yield [10]. Using homogeneous non-ionic amine-based catalysts circumvents most of the economic and environmental drawbacks of the traditional transesterification process. In this case, the removal of typical catalytic species is made easier and the produced methyl ester and glycerol are free of alkali metals such as $\mathrm{Na}, \mathrm{K}, \mathrm{Ca}$ and $\mathrm{Mg}[11,12]$. The most important feature in selecting a catalyst is high activity. The BD production process faces various problems related to the immiscibility of oil and alcohol, which leads to a low interphase mass transfer rate. This results in a 
higher methanol-oil molar ratio, longer reaction time, higher catalyst content, higher temperature and high stirring.

It was reported that the conversion efficiency of oil into fatty acid methyl ester (FAME) is higher under ultrasound than under mechanical stirring [13-15]. Biodiesel production under ultrasonic homogenization has been an expanding research area for the past two decades [16-19]. In BD production, the ultrasonic field is known to produce chemical and physical effects that arise from the collapse of cavitation bubbles [20] and result in a higher rate of BD production. Stavarache et al. [16] estimated that by applying a high frequency ultrasound $(40 \mathrm{kHz})$, the transesterification rate increases quickly, with an increased biodiesel yield. As a consequence, several new BD production plants use the ultrasonication technique [21]. In previous work, we reported a detailed study of vegetable oil transesterification under ultrasound in a continuous flow reactor [22]. The effects of various reaction parameters such as residence time, catalyst concentration, reaction temperature, ultrasound amplitude and power, methanol/oil molar ratio were established.

Singh et al [23] also observed a high decrease in reaction time and unprecedented conversion efficiencies in a short reaction time; they showed that, by using ultrasonication in a batch reactor, a biodiesel yield of more than $99 \%$ can be achieved in a remarkably short duration of five minutes. Furthermore, Kumar et al. [24] carried out the transesterification of coconut oil and reached a maximum yield of $98 \%$ using an amplitude of $60 \%$ and 0.3 cycles per second. Under these conditions, high reaction temperatures $\left(72\right.$ and $\left.89^{\circ} \mathrm{C}\right)$ and preheating before transesterification due to the high melting point of coconut oil were required. Temperature is a complicated factor to control in experiments with US probes, owing to the dissipation of acoustic energy. Boffito et al. [25] suggested that an ultrasound assisted mixing device, which they designed, converts most of the triglycerides with methanol within one minute of pulsed ultrasonic irradiation in the presence of $\mathrm{KOH}$ as a catalyst, while they showed that the reaction with ethanol and isopropanol is also faster than in classical batch reactors. In addition, Martinez-Guerra, and Gude [26] reported pulse sonication (batch reaction) effects using ethanol, methanol and ethanol-methanol mixtures in the conversion of waste cooking oil into biodiesel in the presence of sodium hydroxide. In their study, a maximum biodiesel yield of $99 \%$ was obtained for pulse on-off combination of $7 \mathrm{~s}-2 \mathrm{~s}$ at $150 \mathrm{~W}$ power output, and 9:1 alcohol to oil molar ratio, $1 \mathrm{wt} \%$ of sodium hydroxide, and $1.5 \mathrm{~min}$ reaction time. Various examples of triglyceride transesterification reactions using ethanol, butanol and glycerol were used to illustrate the significance of cavitation in ultrasound assisted reactions [27]. Reyman et al. [28], for example, monitored the ultrasound-assisted conversion of triglycerides to fatty acid methyl ester (FAME) by recording the ratio of infrared peak intensities at 1437 and $1464 \mathrm{~cm}^{-1}$. The proposed infrared method turned out to be inexpensive and independent of the type of oil.

For FAME production, proper mixing is critically important to create sufficient contact between oil and alcohol. In this context, ultrasonication helps by increasing the liquid-liquid interfacial area through emulsification, which is also important for the formation of vapor bubbles and cavitation bubbles in viscous liquids. In the present work, $\mathrm{NaOH}, \mathrm{KOH}, \mathrm{CH}_{3} \mathrm{ONa}$, tetramethyl ammonium hydroxide and four guanidines are tested for transesterification reaction in a batch reactor both under ultrasound and mechanical stirring. The increasing popularity of biodiesel has generated great demand for its commercial production methods, which in turn calls for the development of new technologies such as the ultrasonic continuous flow reactor.

\section{Experimental Section}

\subsection{Materials}

The Canola oil used in the transesterification tests was a commercial edible oil with a characteristic fatty acid composition (C16:0 (4\%), C18:0 (2\%), C18:1 (56\%), C18:2 (26\%), C18:3 $(10 \%)$ and average molecular weight $876.6 \mathrm{Da})$. Minor amounts of long chain (C20:0-C24:0) saturated fatty acids occurred mostly in the 1- and 3-positions. The following were purchased from 
Sigma-Aldrich: Metallic sodium; $\mathrm{KOH}$ pellets; $\mathrm{NaOH}$ pellets; tetramethyl ammonium hydroxide; 1,1,3,3-tetramethylguanidine; 1,3-diphenyl guanidine and dry methanol. Analytical standards of monoglycerides, diglycerides, triglycerides and fatty acid methyl esters were also purchased from Sigma-Aldrich. Finally, propylamine, dicyclohexylcarbodiimide and n-octylamine reagents were purchased from Sigma-Aldrich as well.

\subsection{Catalyst Preparation}

Methanol solution of $\mathrm{KOH}$ and $\mathrm{NaOH}$ were prepared using $\mathrm{KOH}$ and $\mathrm{NaOH}$ pellets. $\mathrm{CH}_{3} \mathrm{ONa}$ was prepared by reacting dry methanol with sodium metal at room temperature. The sodium methoxide content in methanol was adjusted depending on the targeted catalyst/oil ratio.

The synthesis of propyl-2,3 dicyclohexylguanidine (A) consisted of mixing $5 \mathrm{~g}$ propylamine and $6.5 \mathrm{~g}$ of dicyclohexylcarbodiimide with $15 \mathrm{~g}$ of tetrahydofuran and refluxing at $70^{\circ} \mathrm{C}$ for $24 \mathrm{~h}$. The final mixture, which was colorless, was concentrated at $60^{\circ} \mathrm{C}$ using a rotary evaporator. Proton NMR analysis then showed a conversion of more than $99.5 \%$ of the propyl-2,3 dicyclohexylcarbodiimide. (NMR Data: $0.83-\mathrm{CH} 2 \mathrm{CH} 2 \mathrm{CH} 3,1.94-4 \mathrm{H}, 1.98-4 \mathrm{H}, 2.11-4 \mathrm{H}, 2.90-C y c l o h e x a n e, 3.38-3 \mathrm{H}$ ) [29]. 1,3-dicyclohexyl 2 n-octylguanidine (DCOG) (B) was prepared by mixing of $20 \mathrm{~mL}$ dry tert-butanol, $2.58 \mathrm{~g}$ octylamine and $2.06 \mathrm{~g}$ of dicyclohexylcarbodiimide, stirring under nitrogen in a $100 \mathrm{~mL}$ two necked flask at $100{ }^{\circ} \mathrm{C}$ for $19 \mathrm{~h}$. The solvent was evaporated and the product was distilled. The final guanidine yield was 91\%. (Elemental analysis: Calc.: C 75.2\%, H 12.7\%, N 12.3\%; measured: C 75.0\%, H $12.7 \%$, N 12.3\%) [30].

\subsection{Ultrasonic Irradiation Unit}

A Hielscher ultrasonic processor UP 200St (Hielscher Ultrasonics,Teltow,Germany) was used for the transesterification reaction. The ultrasound generator operated at $26 \mathrm{kHz}(200 \mathrm{~W})$ using $60 \%$ amplitude. The sonotrode was made of titanium alloy. The ultrasonic probe had a $7 \mathrm{~mm}$ tip diameter. A temperature controller (Barnant Thermocouple Thermometer) (Barnant Corp., Barrington, USA) was used to control the reaction temperature. The ultrasound batch glass reactor had a volume of $67 \mathrm{~mL}$. For mechanical stirring tests a $250 \mathrm{~mL}$ round bottom flask batch reactor was used. A BECKMAN AvantiTM J-30I centrifuge machine (Beckman Coulter, Miami, USA) was employed for phase separation of the products.

\subsection{Transesterification Reaction}

In this study, experiments were performed to prepare biodiesel from canola oil by using both ultrasonication and mechanical stirring. The aim of these experiments was to compare reaction times for the biodiesel production with maximum yield at specified molar ratio, under ultrasound and mechanical stirring in batch reactors. Another important objective was to collect experimental data using some guanidines as catalysts. These non-ionic organic bases gave promising results for industrial scale, economical and environmentally friendly biodiesel production. In addition, they might be more easily separated from the products than ionic bases.

Transesterification reaction tests were carried out using the ultrasound processor UP 200St. An integrated arrangement was provided for supporting the glass batch reactor $(67 \mathrm{~mL})$, so that the transducer sonotrode should be submerged at the initial separating boundary of the two immiscible liquids, methanol and canola oil. The temperature $\left(35^{\circ} \mathrm{C}\right)$ of the reaction mixture was controlled using a thermostated water bath. The reaction started when a mixture consisting of the desired amount of catalyst dissolved in methanol was mixed with the vegetable oil. Cavitation was created by the irradiation of ultrasonic power with sufficient energy in immiscible liquids. As a result, micro fine bubbles were formed. During the reaction, biphasic representative samples were collected for analysis at different time intervals.

The transesterification reaction tests were carried out under mechanical mixing, using $50 \mathrm{~g}$ of canola oil and $12 \mathrm{~g}$ of methanol (6:1 molar ratio methanol to oil) in a round bottom flask $(250 \mathrm{~mL})$. 
Media with some other methanol to oil ratios (4:1 and 3:1) were also prepared. Different amounts of a homogeneous catalyst $(0.25,0.5,1.0,1.52 .0 \mathrm{wt} \%$ relative to oil) were used. The reaction mixture was mechanically stirred at $65^{\circ} \mathrm{C}$ for different time durations. The polar and non-polar phases of the reacted mixture were separated by centrifugation. Samples of the non-polar phase (FAME) were analyzed by UHPLC.

\subsection{Methyl Ester Analysis}

The polar phase samples contained unreacted monoglycerides (MG), diglycerides (DG), triglycerides (TG) and methyl esters (FAME). These were analyzed by using a UHPLC (UltiMate 3000 Dionex, Dionex Corp., Sunnyvale, CA, USA) equipped with the column AcclaimTM 120, C18, $5 \mu \mathrm{m}, 120$, A $4.6 \times 100 \mathrm{~mm}$, and a UV (Thermo SCIENTIFIC Dionex UltiMate 3000, Dionex Corp., Sunnyvale, CA, USA) variable wavelength detector. Hexane, acetonitrile, and isopropanol were used as HPLC solvents. The solvent flow rate was $2.0 \mathrm{~mL} / \mathrm{min}$. The sample injection volume was $10 \mu \mathrm{L}$ and the peak identification was made by comparing the retention time of the sample compounds with those of the standards. The analysis of each sample was repeated three times.

\section{Results and Discussion}

\subsection{Catalyst Concentration and the Effect of Methanol to Oil Ratio}

Figure 1 shows the effect of catalyst content and methanol to oil ratio on transesterification of the canola oil with sodium methoxide as a catalyst under ultrasound. The experimental observations reported in Figure 1 confirm that use of an ultrasound has no effect in the absence of catalysts. Within a one-minute reaction time, more than $80 \%$ conversion was reached in the presence of $0.5 \mathrm{wt} \%$ catalyst at 6:1 methanol/oil ratio. Therefore, all further experiments were performed at this concentration of catalyst. An additional benefit of a lower catalyst concentration was to limit soap formation.

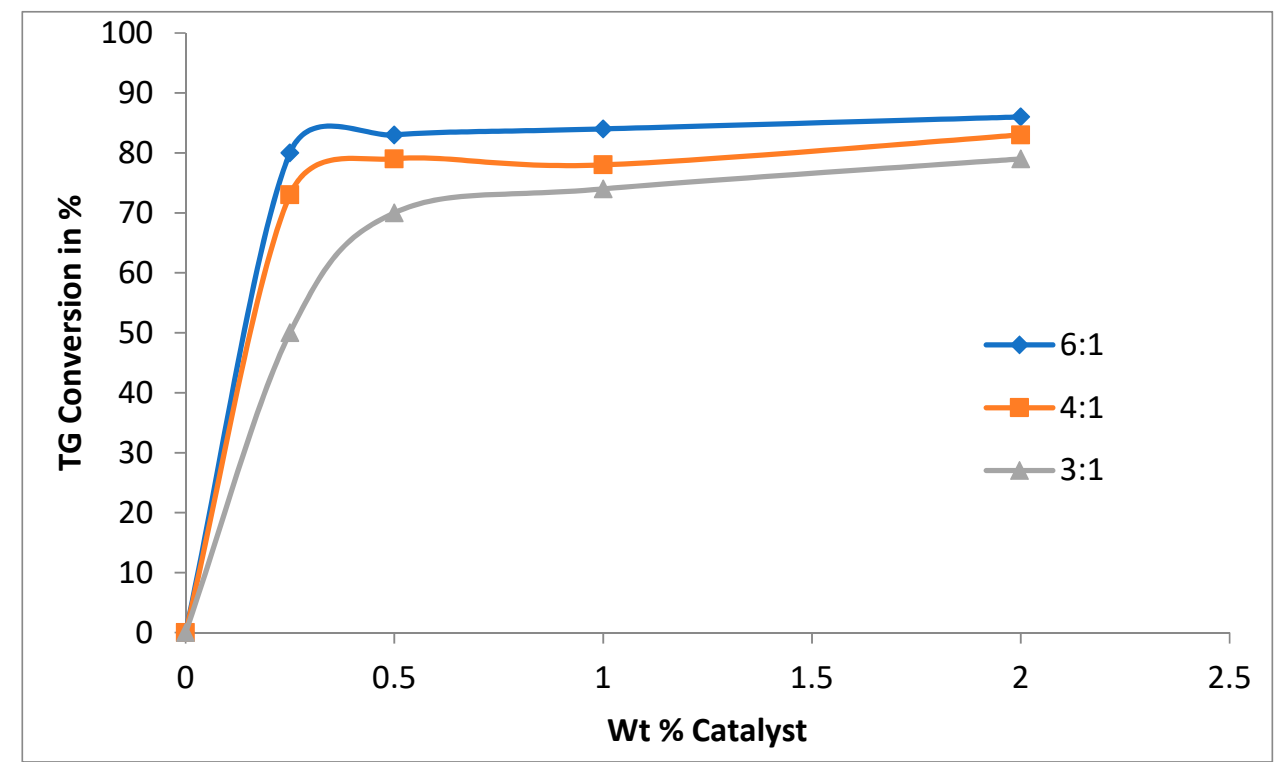

Figure 1. Effect of catalyst concentration on triglyceride conversion in a batch reactor. $0.5 \mathrm{wt} \%$ catalyst $\left(\mathrm{CH}_{3} \mathrm{ONa}\right)$, methanol:oil ratio $(6: 1,4: 1,3: 1)$, ultrasound amplitude $60 \%$, temperature $35^{\circ} \mathrm{C}$, reaction time $1 \mathrm{~min}$.

The transesterification reaction is a series of three successive and reversible reactions transforming a triglyceride molecule into diglyceride, monoglyceride and, finally, into glycerol and the fatty acid methyl esters. If an excess of alcohol is used, glycerine is formed in substantial amounts and the yield of methyl ester is improved. Transesterification reaction can be complete if a large quantity of alcohol 
is used (such as alcohol:oil > 30:1), but this would result in a more expensive methanol/glycerol separation process.

\subsection{Comparison between Ultrasound and Mechanical Stirring in the Presence of $\mathrm{CH}_{3} \mathrm{ONa}$}

The molar ratio of alcohol to oil is one of the important factors that affect the TG conversion efficiency [31]. The comparison of ultrasound and mechanical stirring for molar ratio $(6: 1,4: 1,3: 1)$ shown in Figure 2, illustrates the relationship between TG conversion when exposing reactants to ultrasound (Figure 2B) or mechanical stirring (Figure 2A). The reaction conditions were $0.5 \mathrm{wt} \%$ catalyst $\left(\mathrm{CH}_{3} \mathrm{ONa}\right)$ at different molar ratios of methanol to oil and a temperature of $35^{\circ} \mathrm{C}$ with US, but $65^{\circ} \mathrm{C}$ in the stirred reactor. It can be seen that, in spite of the lower temperature, under ultrasonication the reaction time was much lower compared with the conventional method of using mechanical stirring.
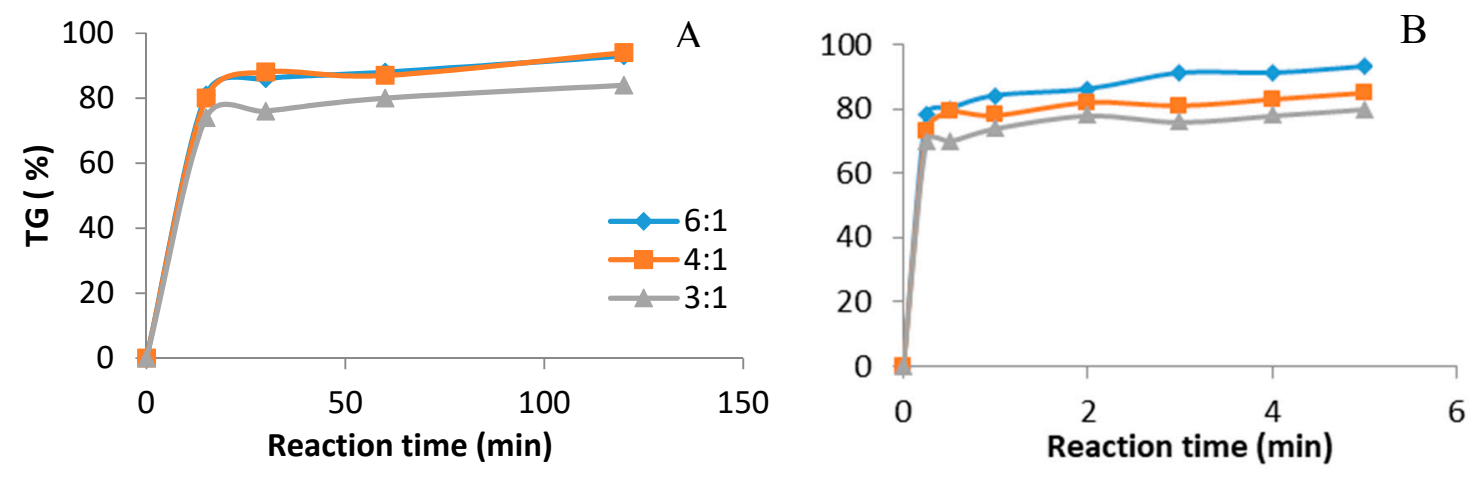

Figure 2. Biodiesel production. Catalyst $\mathrm{CH}_{3} \mathrm{ONa} 0.5$ wt \%, methanol: oil ratio $(6: 1,4: 1,3: 1)$. (A) Mechanical stirring batch reactor, temperature $65^{\circ} \mathrm{C}$. (B) Ultrasound batch reactor, ultrasound amplitude $60 \%$, temperature $35^{\circ} \mathrm{C}$.

\subsection{Comparison between Ultrasound and Mechanical Stirring in the Presence of $\mathrm{KOH}$}

A similar comparison has been made for the canola oil at different methanol to oil molar ratios (6:1, 4:1, 3:1) and $0.5 \mathrm{wt} \% \mathrm{KOH}$ catalyst as shown in Figure 3. A triglyceride conversion of more than $80 \%$ was recorded in a very short period of time under ultrasound. This reaction time is remarkably low compared with that observed under mechanical stirring. This effect is obviously associated to the spectacular increase in transesterification reaction rate brought about by the ultrasonication.
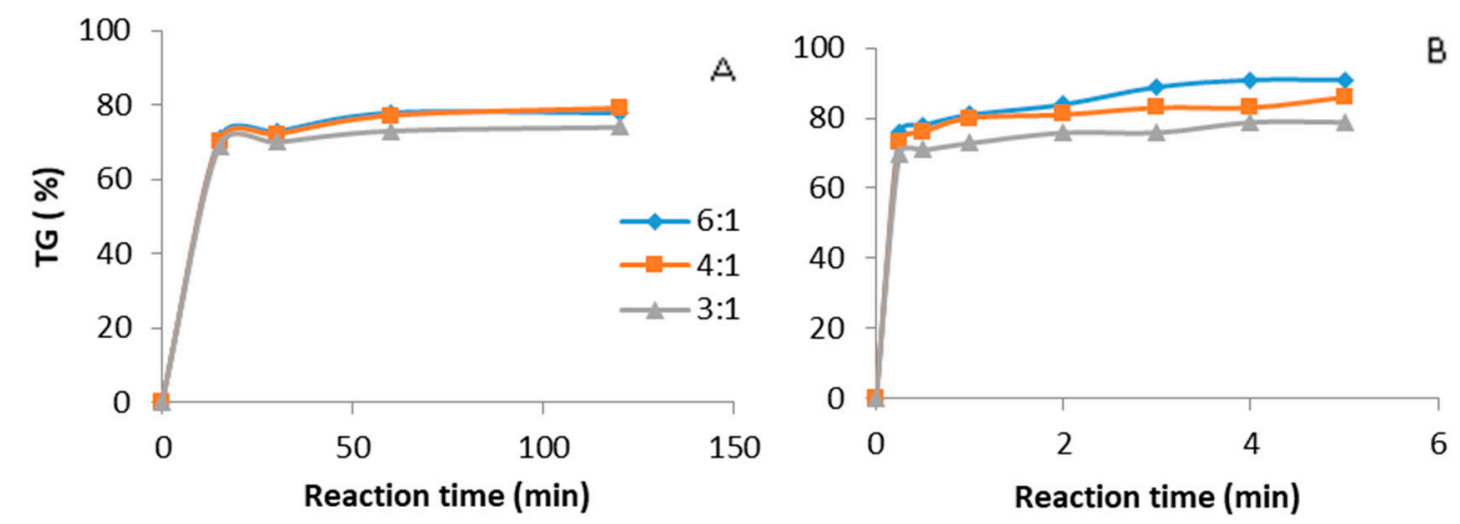

Figure 3. Biodiesel production. Catalyst $\mathrm{KOH} 0.5 \mathrm{wt} \%$, methanol: oil ratio (6:1, 4:1, 3:1). (A) Mechanical stirring batch reactor, temperature $65^{\circ} \mathrm{C}$. (B) Ultrasound batch reactor, ultrasound amplitude $60 \%$, temperature $35^{\circ} \mathrm{C}$. 


\subsection{Comparison between Ultrasound and Mechanical Stirring in the Presence of $\mathrm{NaOH}$}

$\mathrm{NaOH}$ is another catalyst reported for biodiesel production. Figure 4 shows the time evolution of triglyceride conversion with a $\mathrm{NaOH}$ catalyst, using ultrasound (Figure 4B) and mechanical stirring (Figure $4 \mathrm{~A}$ ). The reaction conditions were kept the same as in the above reported tests, namely, a $0.5 \mathrm{wt} \% \mathrm{NaOH}$ catalyst, in presence of different molar ratios of oil to methanol and temperatures of $35^{\circ} \mathrm{C}$ under ultrasound and $65^{\circ} \mathrm{C}$ with mechanical stirring. A triglyceride conversion of more than $80 \%$ was recorded after 1-2 min under ultrasound, whereas a lower value was reached under mechanical stirring after one hour.
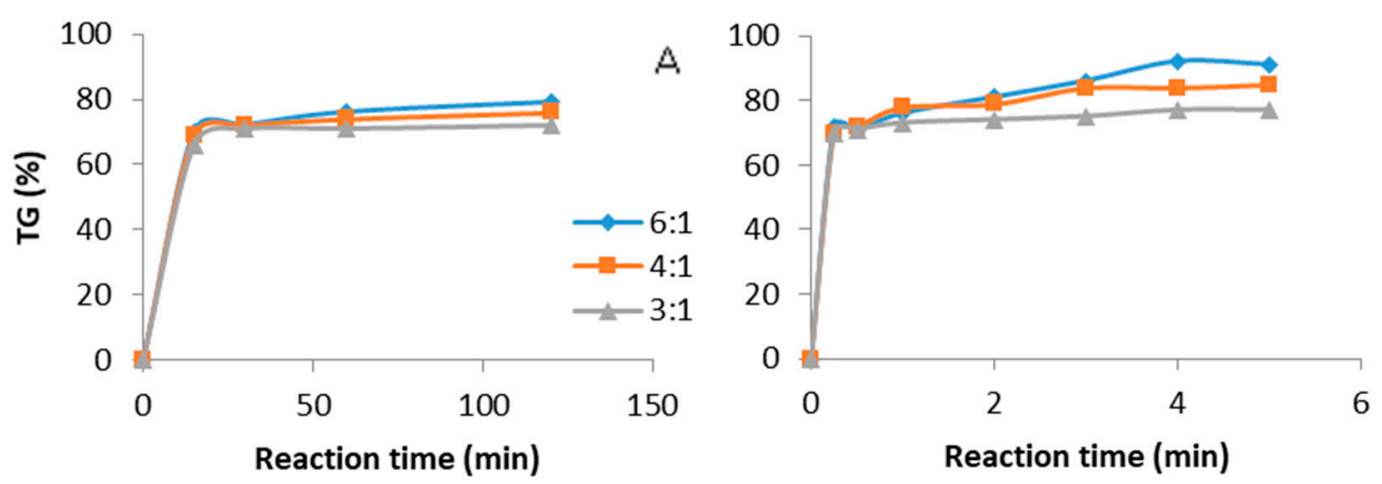

Figure 4. Biodiesel production. Catalyst $\mathrm{NaOH}, 0.5 \mathrm{wt} \%$, methanol: oil ratio (6:1, 4:1, 3:1). (A) Mechanical stirring batch reactor, temperature $65{ }^{\circ} \mathrm{C}$. (B) Ultrasound batch reactor, ultrasound amplitude $60 \%$, temperature $35^{\circ} \mathrm{C}$.

3.5. Comparison between Ultrasound and Mechanical Stirring in the Presence of Tetramethyl Ammonium Hydroxide

Figure 5 shows the comparative study of biodiesel production under ultrasound (Figure 5B) and mechanical stirring (Figure 5A). The catalyst amount was $3 \mathrm{wt} \%$ (tetramethyl ammonium hydroxide), with different methanol to oil molar ratios and temperatures of $35^{\circ} \mathrm{C}$ and $65^{\circ} \mathrm{C}$ respectively. A triglyceride conversion higher than $80 \%$ was recorded under ultrasound after $3 \mathrm{~min}$ at a $6: 1$ methanol/oil molar ratio. This reaction time was again much lower than that observed under mechanical stirring. In this case, the corresponding time was $90 \mathrm{~min}$.
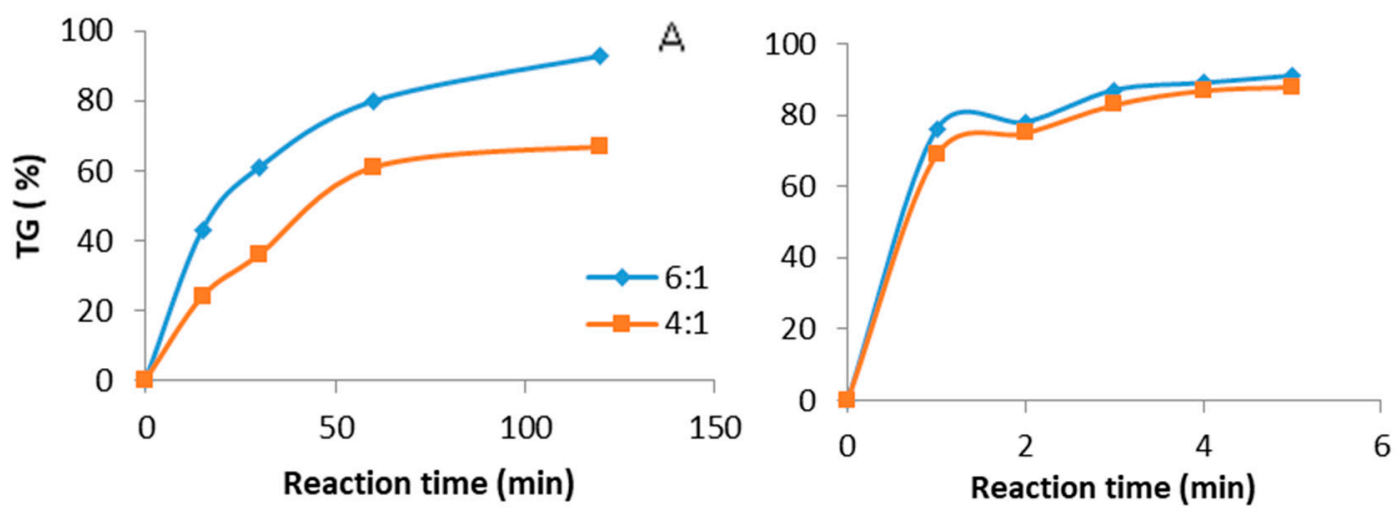

Figure 5. Biodiesel production. Catalyst tetramethyl ammonium hydroxide, $3 \mathrm{wt} \%$, methanol: oil ratio (6:1, 4:1). (A) Mechanical stirring batch reactor, temperature $65^{\circ} \mathrm{C}$. (B) Ultrasound batch reactor, ultrasound amplitude $60 \%$, temperature $35^{\circ} \mathrm{C}$. 


\subsection{Comparison between Ultrasound and Mechanical Stirring Using Guanidines as Catalysts}

In this work, four guanidines were tested as catalysts in the transesterification of canola oil triglycerides by methanol. The designations of these materials are reported in Table 1 along with the values of their $\mathrm{pKa}$ in $\mathrm{CH}_{3} \mathrm{CN}$ [32].

Table 1. Designation of the guanidines used as catalysts.

\begin{tabular}{cccc}
\hline Designation & Formula & Designation & pKa \\
\hline A & Propyl-2,3-dicyclohexyl guanidine & PCHG & 30.7 \\
B & 1,3-dicyclohexyl 2 n-octyl guanidine & DCOG & 31.1 \\
C & $1,1,3,3$ tetramethyl guanidine & TMG & 23.16 \\
D & 1,3 diphenyl guanidine & DPG & 10.1 \\
\hline
\end{tabular}

Figure 6 shows the effect of methanol/oil ratio at a given $3 \mathrm{~mol} \%$ content of guanidine A as the catalyst under ultrasound. As expected, increasing the methanol/oil molar ratio from 3:1 to 4:1 results in a significant increase of the reaction rate.

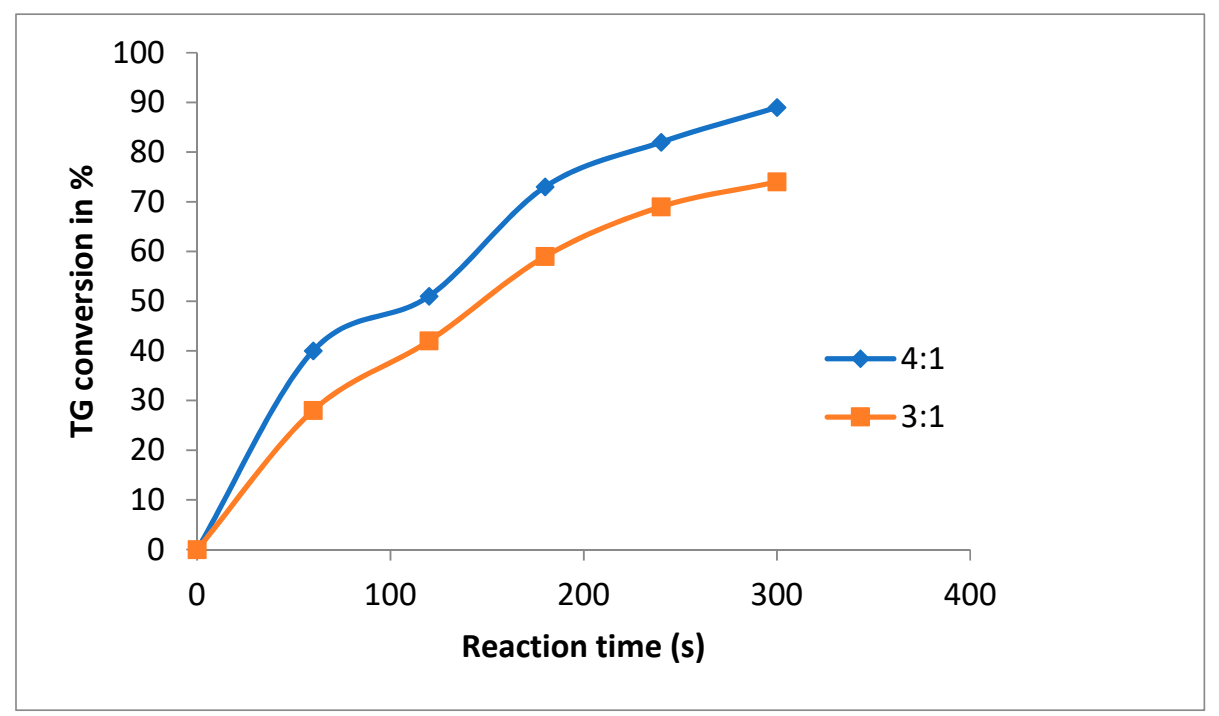

Figure 6. Ultrasound biodiesel production in batch reactor, catalyst (guanidine A) 3\% mol, 4:1 and 3:1 (methanol: Canola oil) US 60\% amplitude, $35^{\circ} \mathrm{C}$.

As reported in Figure 7, the experiments carried out by using guanidine A as the catalyst show the beneficial effect of changing catalyst content from 3 to $5 \mathrm{~mol} \%$ (with respect to oil), while other parameters were fixed at $35{ }^{\circ} \mathrm{C}$ and an ultrasound amplitude $60 \%$. Figure 7 shows that the increase of catalyst content (guanidine A) from 3 to $5 \%$ results in an increase in FAME yield, from 89 to $95 \%$ after five minutes.

Figure 8 shows the TG conversion evolution under ultrasound (Figure $8 \mathrm{~B}$ ) and mechanical stirring (Figure 8A). In the presence of ultrasound, guanidine (A) and guanidine (B) transesterification reaction rates were similarly high. Guanidine (C) and guanidine (D) showed lower activity with only a small triglyceride conversion observed. In the case of mechanical stirring, reaction guanidine (A) and guanidine (B) yielded low conversions over the same length of time (five minutes) and guanidine (C) and guanidine $(\mathrm{D})$ showed no reaction. 


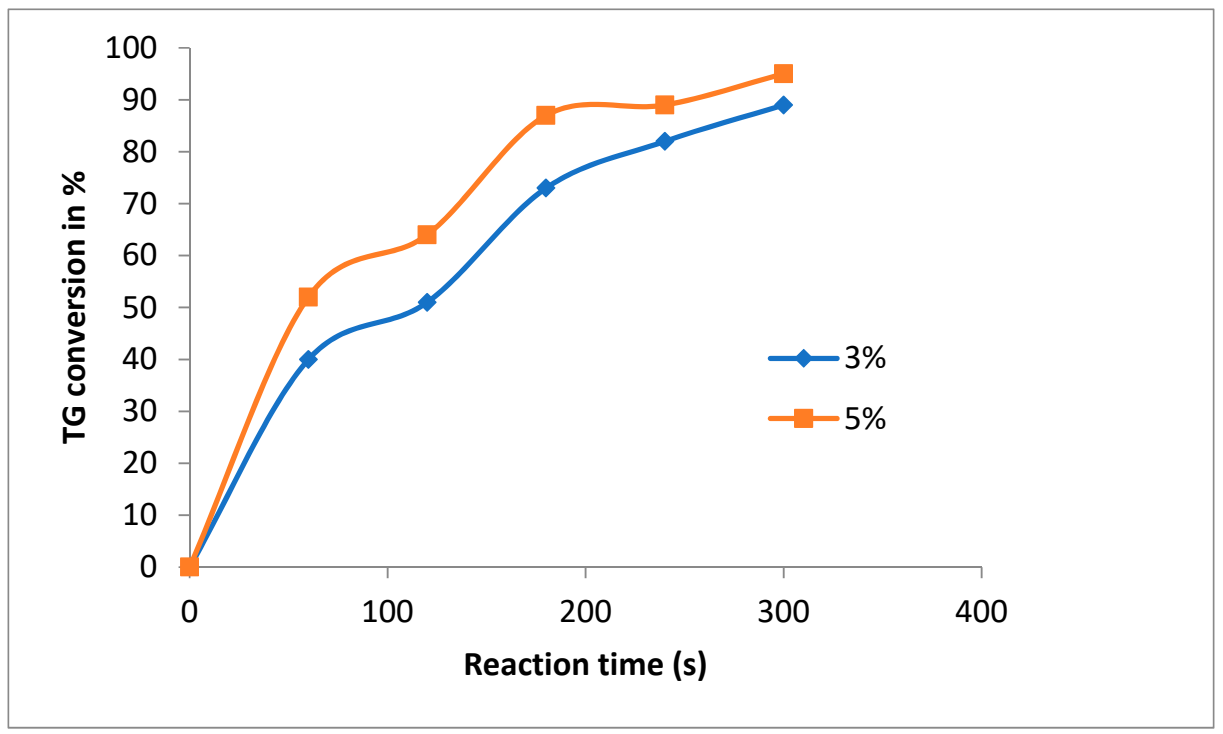

Figure 7. Ultrasound in batch reactor 4:1 (methanol:canola oil), Catalyst (guanidine A) 3 and 5\% mol, US $60 \%$ amplitude, temperature $35^{\circ} \mathrm{C}$.
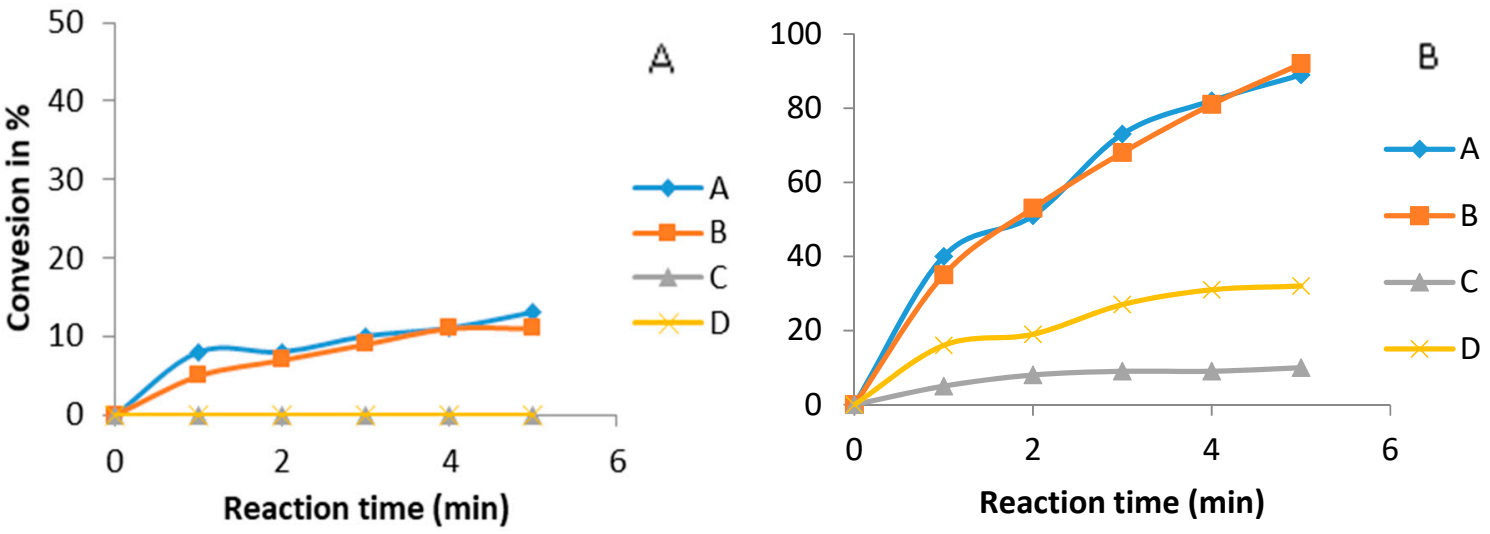

Figure 8. Biodiesel production under various guanidines ( $3 \% \mathrm{~mol})$. (A) Mechanical stirring batch reactor: (methanol:canola oil) 4:1, temperature $65^{\circ} \mathrm{C}$; (B) Ultrasound batch reactor: (methanol:canola oil) $4: 1,60 \%$ US amplitude, temperature $35^{\circ} \mathrm{C}$.

This reduced activity is related to a lower base strength, which decreases when the guanidinium cation is less symmetric (e.g., TMG), or has no substituents with a positive inductive effect (e.g. DPG). The activity order of the catalysts was PCHG $=$ DCOG $>$ DPG $>$ TMG, which is the order of pKa as shown in Table 1.

The two guanidines PCHG and DCOG (guanidines A and B) are therefore of particular interest for application in biodiesel production under ultrasound in a continuous flow reactor. As seen from the comparison of Figures 2-8, their activity is on the same order of magnitude as such classic homogeneous basic catalysts as $\mathrm{CH}_{3} \mathrm{ONa}, \mathrm{NaOH}, \mathrm{KOH}$; however, by not being ionized, they do not generate sodium or potassium ions and because of their organic nature, they may be more easily separated from the polar phase and continuously recycled to the ultrasonic reactor.

Whatever the catalyst among those reported here, the accelerating effect of ultrasound is spectacular and will result in drastic reduction in reactor volume for BD large scale production.

\section{Conclusions}

In this work, the transesterification reaction of canola oil with methanol and different types of catalysts using both mechanical stirring and ultrasonication were investigated. Ultrasound 
homogenization proved suitable for biodiesel production using canola oil in a good yield and high conversion. The efficiency of mass transfer in the ultrasound field enhanced the rate of transesterification reaction as compared with mechanical stirring. Running this reaction under ultrasonic cavitation is an energy efficient and industrially viable alternative for biodiesel production. Propyl-2,3 dicyclohexylguanidine (PCHG) and 1,3-dicyclohexyl 2 n-octylguanidine (DCOG) have both been shown to be of special interest in this context.

Author Contributions: Conceptualization, S.K.; investigation, K.S.; writing -original draft preparation, K.S.; writing-review and editing, S.K.; visualization, K.S.; supervision, S.K.

Funding: This researchwas fundedby Natural Sciences and Engineering Council of Canada- Grant\# RGPIN2015-06175.

Conflicts of Interest: The authors declare no conflict of interest.

\section{References}

1. The Royal Society. Sustainable Biofuel: Prospects and Challenges; The Royal Society: London, UK, 2008.

2. Talebian-Kiakalaieh, A.; Saidina Amin, N.A.; Mazaheri, H. A review on novel process of biodiesel production from waste cooking oil. Appl. Energy 2013, 104, 683-710. [CrossRef]

3. Schuchardt, U.; Sercheli, R.; Vargas, R.M. Transesterification of Vegetable Oils: A Review. J. Braz. Chem. Soc. 1998, 9, 199-210. [CrossRef]

4. Canakci, M.; Gerpen, J.V. A pilot plant to produce biodiesel from high free fatty acid feedstocks. Trans. ASAE 2003, 46, 945-954. [CrossRef]

5. Gerpen, J.V. Biodiesel processing and production. Fuel Process Technol. 2005, 86, 1097-1107. [CrossRef]

6. Jeong, G.T.; Park, D.H. Batch (one- and two-stage) production of biodiesel fuel from rapeseed oil. Biotechnol. Appl. Biochem. 1996, 131, 668-679. [CrossRef]

7. Bournay, L.; Cassanave, D.; Delfort, B.; Hillion, G.; Chadorge, J.A. New heterogeneous process for biodiesel production: A way to improve the quality and the value of the crude glycerin produced by biodiesel plants. Catal. Today 2005, 106, 190-192. [CrossRef]

8. Muhammad, N.; Elsheikh, Y.A.; Mutalib, M.I.A.; Bazmi, A.A.; Khan, R.A.; Khan, H.; Rafiq, S.; Man, Z.; Khan, I. An overview of the role of ionic liquids in biodiesel reactions. J. Ind. Eng. Chem. 2015, 21, 1-10. [CrossRef]

9. Dossin, T.F.; Reyniers, M.F.; Berger, R.J.; Marin, G.B. Simulation of heterogeneously MgO-catalyzed transesterification for fine-chemical and biodiesel industrial production. Appl. Catal. B Environ. 2006, 67, 136-148. [CrossRef]

10. Freedman, B.; Pryde, E.H.; Mounts, T.L. Variables affecting the yield of fatty esters from transesterified vegetable oils. J. Am. Oil Chem. Soc. 1984, 61, 1638-1643. [CrossRef]

11. Cerce, T.; Peter, S.; Weidner, E. Biodiesel-transesterification of biological oils with liquid catalysts: Thermodynamic properties of oil-methanol-amine mixtures. Ind. Eng. Chem. Res. 2005, 44, 9535-9541. [CrossRef]

12. Tang, Z.; Wang, L.; Yang, J. Transesterification of rapeseed oil catalyzed by liquid organic amine in supercritical methanol in a continuous tubular-flow reactor. Eur. J. Lipid Sci. Technol. 2008, 110, 747-753. [CrossRef]

13. Stavarache, C.; Vinatoru, M.; Maeda, Y. Aspect of ultrasonically assisted transesterification of various vegetable oils with methanol. Ultrason. Sonochem. 2007, 14, 380-386. [CrossRef] [PubMed]

14. Omotola, B.; Leslie, P.; Bamikole, A.; Farouk, A. Low-Cost feedstock conversion to biodiesel via ultrasound technology. Energies 2009, 3, 1691-1703.

15. Kumar, D.; Kumar, G.; Poonam Singh, C.P. Ultrasonic-assisted transeterification of jatropha oil using solid catalyst, $\mathrm{Na} / \mathrm{SiO}_{2}$. Ultrason. Sonochem. 2010, 17, 839-844. [CrossRef] [PubMed]

16. Stavarache, C.; Vinatoru, M.; Nishimura, R.; Maeda, Y. Conversion of vegetable oil to Biodiesel using ultrasonic irradiation. Chem. Lett. 2003, 32, 716-717. [CrossRef]

17. Taleyarkhan, R.P.; Cho, J.S.; West, C.D.; Nigmatulin, R.I.; Block, R.C. Additional evidence of nuclear emissions during acoustic cavitation. Phys. Rev. 2004, 69, 361-369. 
18. Encinar, J.M.; González, J.F.; Rodríguez, J.J.; Tejedor, A. Biodiesel fuels from vegetable oils: Transesterification of Cynara cardunculus L. Oils with Ethanol. Energy Fuels 2002, 16, 443-450. [CrossRef]

19. Encinar, J.M.; Juan, F.; Gonzalez, J.F.; Rodriguez, J.R. Biodiesel from Used Frying oil: Variables Affecting the Yields and Characteristics of the Biodiesel. Ind. Eng. Chem. Res. 2005, 44, 5491-5499. [CrossRef]

20. Hanh, H.D.; Dong, N.T.; Okitsu, K.; Nishimura, R.; Maeda, Y. Biodiesel production through transesterification of triolein with various alcohols in an ultrasonic field. Renew. Energy 2009, 34, 766-768. [CrossRef]

21. Kotrba, R. Ultrasonic biodiesel processing. Biodiesel Magazine, 19 May 2010.

22. Shinde, K.; Nohair, B.; Kaliaguine, S. A Parametric Study of Biodiesel Production Under Ultrasounds. Int. J. Chem. React. Eng. 2017, 15, 117-125. [CrossRef]

23. Singh, A.K.; Fernando, S.D.; Hernandez, R. Base-catalyzed fast transesterification of soybean oil using ultrasonication. Energy Fuels 2007, 21, 1161-1164. [CrossRef]

24. Kumar, D.; Kumar, G.; Poonam; Singh, C.P. Fast, easy ethanolysis of coconut oil for biodiesel production assisted by ultrasonication. Ultrason. Sonochem. 2010, 17, 555-559. [CrossRef] [PubMed]

25. Boffito, D.C.; Galli, F.; Martinez, P.R.; Pirola, C.; Bianchi, C.L.; Patience, G.S. Transesterification of Triglycerides in a New Ultrasonic-Assisted Mixing Device. Chem. Eng. Trans. 2015, 43. [CrossRef]

26. Martinez-Guerra, E.; Gude, V.G. Determining optimum pulse mode for ultrasound enhanced biodiesel production. J. Ind. Eng. Chem. 2016, 35, 14-19. [CrossRef]

27. Shinde, K.; Kaliaguine, S. Triglycerides Transesterification Reactions under Ultrasounds. ChemistrySelect 2016, 1, 6008-6010. [CrossRef]

28. Reyman, D.; Saiz Bermejo, A.; Ramirez Uceda, I.; Rodriguez Gamero, M. A new FTIR method to monitor transesterification in biodiesel production by ultrasonication. Environ. Chem. Lett. 2014, 12, 235-240. [CrossRef]

29. Maliverney, C.; Sur Bibost, T.; Ireland, S.J. Method for Sealing and Assembling Components of a Drive Train. U.S. Patent 8,470,950 B2, 25 June 2013.

30. Schuchardt, U.; Vargas, R.M.; Gelbard, G. Alkylguanidines as catalysts for the transesterification of rapeseed oil. J. Mol. Catal. A Chem. 1995, 99, 65-70. [CrossRef]

31. Bautista, L.F.; Vicente, G.; Rodriguez, R.; Pacheco, M. Optimisation of FAME production from waste cooking oil for biodiesel use. Biomass Bioenergy 2009, 33, 862-872. [CrossRef]

32. Sharma, Y.C.; Singh, B.; Upadhyay, S.N. Advancements in development and characterization of biodiesel: A review. Fuel 2008, 87, 2355-2373. [CrossRef] 